UDC: 316.624.3:37.015.324.2[005.336.2-029:3]

DOI: 10.26697/ijes.2019.2.30

\section{Formation of Social Competence to Prevent Bullying in Schools}

Post-Graduate Student Hubarieva D. V. ${ }^{1}$

${ }^{1}$ National Pedagogical Dragomanov University, Ukraine

\section{Abstract \\ Background:}

The present picture of the world faced by society is the problem of bullying (harassment). Recent times the media are increasingly covered by the aggressive behavior of adolescents, the harassment of peers. Science has long been interested in this problem, but at the same time, the number of available theories require additional theoretical analysis, and in the future - new empirical studies that could become the basis for creating more accurate knowledge.

The scale of this problem encompasses not only educational institutions, but society as a whole. The aggressive behavior of children does not remain only behind the walls of educational institutions, but continues its existence beyond the boundaries that lead to massive problems of social life of society. Therefore, the subject of this article becomes relevant. To solve this problem, it is necessary to identify and resolve the causes, and then form the algorithm of action.

The purpose of the paper is to prove the hypothesis that the main reason for the manifestation of the bullying is the unformed social competence at the age of junior schoolboy.

\section{Methods:}

To ground the necessity of social competence formation as a means of solving a bullying problem at schools, a set of theoretical methods of research has been applied: deduction and induction, analysis and synthesis, comparison, generalization.

\footnotetext{
Results:

Understanding the factors contributing to social harassment, including knowledge of correlates and causes of bullying, will contribute to the proper prevention, detection and prevention of the manifestation of the phenomenon of bullying. Particular attention is required to the age of junior schoolchildren.

After all, this is, firstly, the initial link in the socialization of the individual. Second, according to the age-old psychological and physiological characteristics of this age group, the child begins to consciously orient in interpersonal relationships, receives his social role and, in the development of mental activities, is actively involved in life-communicative situations.

An important factor is that at the age of primary school brain regions become mature which are responsible for perception of the surrounding people, and multi-level types of thinking are formed.
}

All the experience acquired by a child at this sensitive period influences very much the duration and efficiency of brain bonds connections.

An important task of the modern educational paradigm is to lay a solid foundation for the formation of moral values and norms for children for further application in a social institution.

The study allows us to state that the term "bullying" in the broad sense is identified with an antisocial behavior that points to socially incompetent children.

This descriptive method has provided the basis for a thorough analysis of the opposite definition, namely, "social competence", and its impact on the subsequent manifestation of the phenomenon of "bullying".

In addition, the analysis of scientific literature showed the connection between the psycho-physiological characteristics of a younger student with the formation of social competence and the prevention of manifestation of aggressive behavior in general.

\section{Conclusions:}

Thus, the analysis of scientific literature made it possible to assert that we will not be able to completely eliminate this problem, but we are able to prevent severe forms of harassment among children and reduce the amount of their manifestation due to timely social competence at the age of junior schoolchildren.

\author{
Information about the author: \\ Hubarieva Daria Viacheslavivna - Post-Graduate \\ Student, National Pedagogical Dragomanov \\ University, Kyiv, Ukraine. \\ Research interests: bullying, social pedagogy, \\ psychological health; http://orcid.org/0000-0002-4513- \\ 8586.
}

\section{Corresponding Author:}

Hubarieva Daria Viacheslavivna

\section{Corresponding Author's Email:}

kameta2014@ukr.net 